논문 2012-50-6-16

\title{
$\mathrm{XRF}$ 시스템용 효율적인 Trapezoidal 필터 및 최대값 검출 회로 설계
}

\section{( Design of Efficient Trapezoidal Filter and Peak Value Detection Circuit for XRF Systems )}

\author{
박 철 암*, 정 진 균 ${ }^{* *}$ \\ ( Zheyan Piao ${ }^{\odot}$ and Jin-Gyun Chung ) \\ 요 약
}

$\mathrm{XRF}$ 시스템에서 디지털 방식으로 펄스를 합성하는 기술은 현재 다양하게 발전 되면서 기존의 아날로그 방식을 대신하고 있다. XRF 시스템에서는 펄스의 높이를 분석하기 위해 주로 trapezoidal 필터를 사용한다. 본 논문에서는 trapezoidal 필터의 하드웨어 구현을 위한 효율적인 구조를 제안한다. 또한 측정 오차가 기존 알고리즘에 의한 오차의 절반으로 감소되면서 효율 적인 하드웨어 구현이 가능한 최대값 검출 알고리즘을 제안한다. 제안한 알고리즘은 하드웨어 언어인 Verilog HDL로 설계하 고FPGA로 구현하였으며 테스트보드를 제작하여 성능을 검증하였다.

\begin{abstract}
In XRF systems, various techniques have been developed for the synthesis of pulse shapes using digital methods instead of traditional analog methods. Trapezoidal pulse shaping algorithms can be used for digital multi-channel pulse height analysis in X-ray spectrometer systems. In this paper, an efficient trapezoidal filter architecture is presented. In addition, we present a hardware-efficient peak value detection algorithm. By the proposed algorithm, peak value detection error is decreased by half compared with the conventional algorithm. The proposed Digital Pulse Processing(DPP) algorithm is designed using Verilog HDL and implemented using an FPGA on a test board. It is demonstrated that the implemented DPP board works successfully in practical XRF systems.
\end{abstract}

Keywords: XRF System, trapezoidal filter, peak value detection, digital pulse processing.

\section{I. 서 론}

$\mathrm{X}$ 선 형광분석은 물질의 특성을 측정하기 위해서 널 리 사용되는 방법 중의 하나이다. 측정 시료에 $\mathrm{X}$-선을 조사하면 시료를 구성하고 있는 원자들이 외부에서 충 분한 에너지를 받아서 여기 상태(excited state)가 되었

\footnotetext{
* 학생회원, ${ }^{* *}$ 평생회원, 전북대학교 전자공학부

(Department of Electronic Engineering, Chonbuk National University)

※ 본 연구는 교육과학기술부와 한국연구재단의 지역 혁신인력양성사업으로 수행된 연구결과임.

(c) Corresponding Author(E-mail: capark@jbnu.ac.kr) 접수일자 2013년3월15일, 수정완료일 2013년5월21일
}

다가 다시 기저 상태(ground state)로 전이 될 때 원자 의 고유한 특성을 갖는 2 차 $\mathrm{X}$-선이 발생한다. 이것을 $\mathrm{XRF}$ (X-Ray Fluorescence)라고 하며, 이때 발생한 형 $\mathrm{X}$-선은 원소의 종류에 따라 서로 다른 에너지를 갖는 다 $^{[1]}$.

일반적인 $\mathrm{XRF}(\mathrm{X}$-Ray Fluorescence)시스템 검출기 에서 검출된 신호는 그림 1 과 같이 상승 시간이 매우 짧고 하강 시간이 긴 exponential 형태의 신호이다. Exponential 형태 신호의 최대값은 측정 원소의 에너지 대역을 나타내며 그 크기를 정확히 찾아내는 것이 매우 중요하다. 하지만 exponential 신호의 특성 때문에 신호 의 최대값을 정밀하게 계산하는 것은 용이하지 않다. 


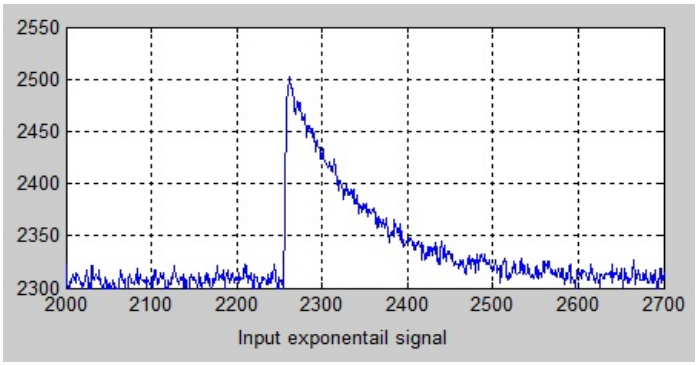

그림 1. XRF 시스템 입력신호

Fig. 1. Input signal of XRF systems.

$\mathrm{XRF}$ 시스템 검출기에서 출력되는 신호가 exponential 펄스인 경우 trapezoidal 필터를 사용함으로 써 입력 신호의 정보를 용이하게 추출할 수 있다 ${ }^{[23]}$.

Trapezoidal 필터는 입력 펄스를 trapezoid(사다리꼴) 모양으로 변환하며 변환된 trapezoid의 flat top 부분의 값으로 부터 입력 펄스의 최대값을 결정한다. 현재 가 장 많이 사용하고 있는 Trapezoidal 필터는 convolution 을이용한 알고리즘 ${ }^{[4]}$ 과 전달함수를 이용한 알고리즘이 다 $^{[5]}$.

본 논문에서는 XRF시스템에 적용되는 두 trapezoidal 필터 알고리즘을 비교하고 효율적인 구현을 위한 하드 웨어 구조를 제안한다. 또한, 필터 출력신호로부터 최대 값을 효율적으로 구하기 위한 최대값 검출 알고리즘을 제안한다. 제안한 알고리즘은 Verilog $\mathrm{HDL}$ 로 설계하여 Quartus 포 검증을 하였으며 FPGA 보드를 이용하여 구현하고 검증하였다.

\section{Trapezoidal Pulse Shaper 알고리즘}

\section{Trapezoidal 필터}

경원소에서 중금속에 이르기 까지 정량적으로 분석 할 수 있는 $\mathrm{XRF}$ 시스템의 $\mathrm{DPP}($ Digital Pulse Processing) 유니트는 그림 2의 점선으로 표시한 부분 과 같이 디지털 펄스처리 블록, peak value 검출 블록, 히스토그램 구성블록으로써 하나의 FPGA chip 내에 구현한다. Peak value들을 토대로 구성된 히스토그램으

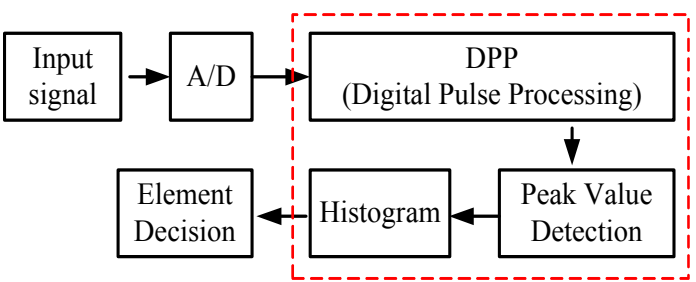

그림 2. XRF 시스템 DPP Unit 블록도

Fig. 2. DPP unit block diagram of XRF systems.
로부터 측정 원소의 특성을 분석할 수 있다.

\section{가. Trapezoidal Pulse Shaper 알고리즘}

그림 3 과 4는 각각 convolution을 이용한 trapezoidal 필터와 전달함수를 이용한 trapezoidal 필터의 하드웨어 구조이다. 그림에서 보이는 바와 같이 두 알고리즘은 모두 세 개의 블록으로 나뉘어 있다. Block1의 파라미 터 $k$ 는 trapezoid의 상승구간 길이이고, 파라미터 $m$ 은 trapezoid의 flat-top 부분의 길이이다 (그림 10 참조). Flat-top부분의 길이는 최대값 검출에 결정적인 영향을 미치지 않으므로 하드웨어 구현 시 본 논문에서는 $m$ 값 을 $k / 3$ 로 고정하였다.

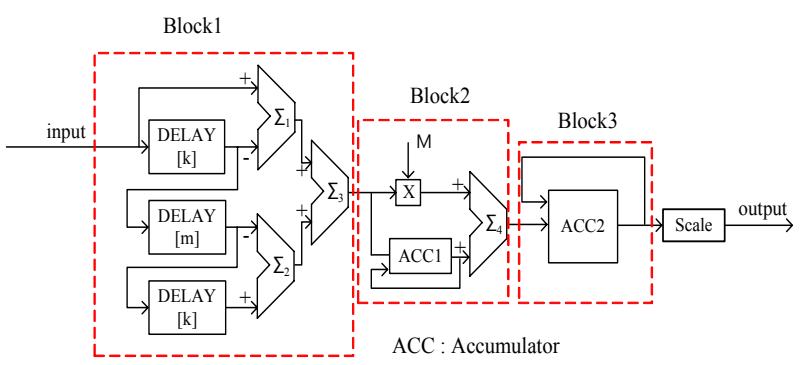

그림 3. Convolution을 이용한 알고리즘 블록도

Fig. 3. Block diagram of trapezoidal filter using convolution algorithm.

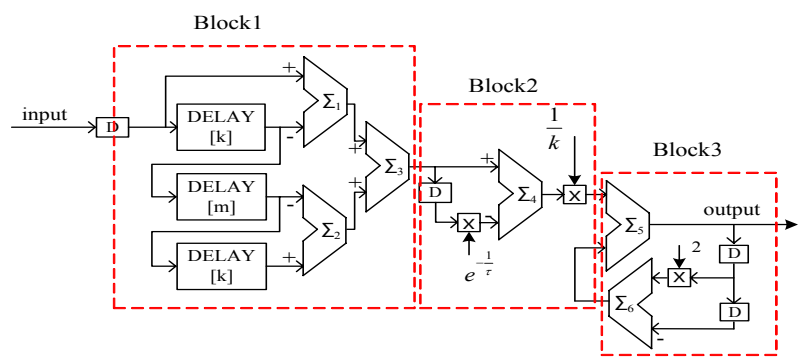

그림 4. 전달함수를 이용한 알고리즘 블록도

Fig. 4. Block diagram of trapezoidal filter using transfer function algorithm.

\section{나. 알고리즘 시뮬레이션 결과 비교}

그림 5는 MATLAB을 이용하여 동일한 입력 exponential 펄스 신호에 대해 trapezoidal 필터의 출력 을 계산한 결과이다. 기저값과 최대값의 차이가 원하는 peak value이다. 두 필터의 출력을 비교하면 peak value의 정확도에는 큰 차이가 없으나 convolution을 이 용한 필터의 경우 그림 5 에 보인 바와 같이 출력값이 크기 때문에 워드길이가 길어야하고 출력단에 전체 scale을 다운 시키는 나눗셈 회로를 적용하여야 정확한 출력값을 얻을 수 있다. 


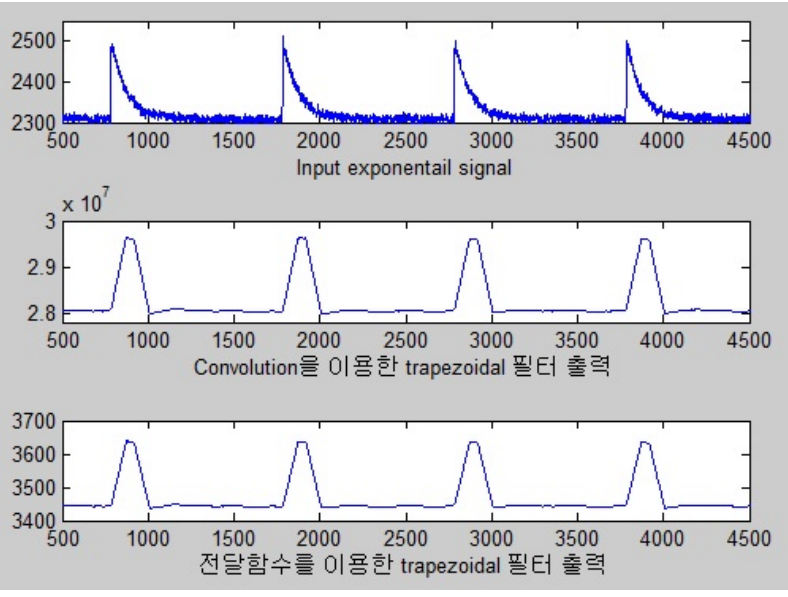

그림 5. 두 개의 trapezoidal 필터 출력

Fig. 5. Comparison of two trapezoidal filter output signals.

표 1. Trapezoidal 필터 알고리즘의 하드웨어 면적 비 교

Table 1. Hardware comparison of trapezoidal filters.

\begin{tabular}{|c|c|c|}
\hline & Convolution & Transfer function \\
\hline Gate & 46121 & 27415 \\
\hline
\end{tabular}

두 알고리즘을 하드웨어로 설계 하였을 때 표 1에 보 인 바와 같이 전달함수 알고리즘에 의한 하드웨어 면적 은 convolution 알고리즘에 의한 하드웨어 면적의 약 $60 \%$ 밖에 되지 않는다. 따라서 본 논문에서는 전달함수 를 이용한 trapezoidal 필터 알고리즘을 사용하여 $\mathrm{DPP}$ 유니트를 구현 한다.

다. Trapezoidal 필터 알고리즘의 하드웨어 구조개선 본 절에서는 전달함수를 이용한 trapezoidal 필터의 효율적 구현을 위한 개선 방안을 제시한다. 그림 4 와 같이 trapezoidal 필터의 block 2에서 $e^{-1 / \tau}$ 을 곱하는 연산을 수행한다. $\tau$ 값은 입력신호의 time constant에 따라 변화 하므로 time constant가 결정되면 $\tau$ 값도 정 해진다. 그러므로 $e^{-1 / \tau}$ 값은 Taylor 시리즈를 이용하 여 근사화 시킴으로써 알고리즘을 더 효율적으로 구현 할 수 있다. 지수함수의 Taylor 시리즈를 이용한 근사 화 식은 다음과 같다.

$$
e^{x} \cong 1+x+\frac{x^{2}}{2 !}+\frac{x^{3}}{3 !}+\cdots+\frac{x^{n}}{n !} .
$$

$\mathrm{XRF}$ 시스템의 다양한 입력 데이터로 시뮬레이션한 결과 $n=3$ 인 경우에 원하는 결과를 얻을 수 있음을 알 수 있다. 따라서 $n=3$ 으로 선택함으로서 하드웨어 구현을 효

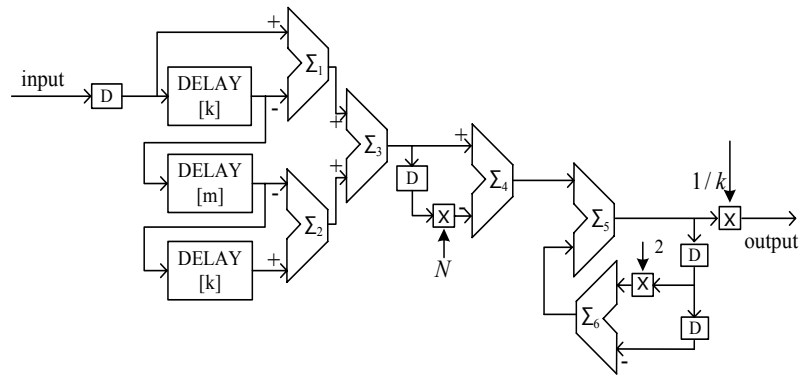

그림 6. Trapezoidal 필터의 구현을 위한 개선된 구조

Fig. 6. Improved architecture of trapezoidal filter.

율적으로 할 수 있다.

그림 4 의 block 3 에서는 입력신호와 $1 / k$ 의 곱셈 연산 을 수행한다. $k$ 값이 크면 $1 / k$ 값은 작아지므로 정확한 출력을 얻기 위해서는 곱셈기 및 출력의 워드길이를 증 가시켜야한다. 상수곱셈을 입력 단에서 수행하든 출력 단에서 수행하든 최종 출력 값에는 영향을 미치지 않으 므로 본 논문에서는 시스템의 정확성 및 효율성을 고려 하여 그림 6과 같이 곱셈을 feedback loop의 출력 단에 배치한다. 그림 6은 tapezoidal 필터의 하드웨어 구현을 위한 개선된 구조이다. 그림 6 에서 $N$ 은 식 (1)에서 $n=3$ 으로 선택하여 근사화한 값을 나타낸다.

\section{III. 최대값 검출 알고리즘}

그림 7에서 보인 바 와같이 exponential 신호의 최대 값과 trapezoid의 최대값은 동일하다. 하지만 입력 exponential 신호의 최대값 까지 상승 하는데 걸리는 시 간에 따라 trapezoidal 펄스는 그림 7 에서와 같이 ballistic deficit 현상이 발생한다 ${ }^{[6]}$. 본 논문에서는 ballistic deficit 현상 때문에 최대값 까지 도달하지 못 하는 앞부분을 제외하고 trapezoidal 펄스의 flat-top 뒷부분에서 최대값을 검출한다.

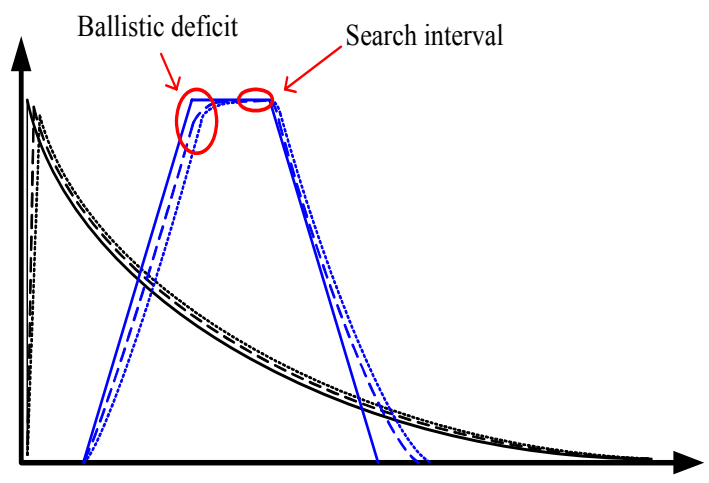

그림 7. Trapezoidal 필터의 최대값 검출 구간

Fig. 7. Trapezoidal filter peak detection interval. 


\section{1. 기존 최대값 검출 알고리즘}

Trapezoidal 펄스의 최대값을 검출하기 위해서 trapezoidal 펄스의 적분 값을 이용할 수 있다 ${ }^{[7]}$. 다음 식은 trapezoidal 펄스의 적분식이다.

$$
s(t)=\int_{t-T}^{t} v(t) d t .
$$

식 (2)에서 $v(t)$ 는 trapezoid 신호이고, $T$ 는 flat-top 부 분의 길이다. 식 $(2)$ 는 아래와 같이 두 개의 적분 식으 로 표현할 수 있다.

$$
s(t)=\int_{0}^{t} v(t) d t-\int_{0}^{t-T} v(t) d t .
$$

다음 식 (4)의 조건이 성립하면 식 (3)은 식 (5)와 같 이 표현할 수 있다.

$$
\begin{aligned}
& v(t)=0,-T<t<0, \\
& s(t)=\int_{0}^{t}[v(t)-v(t-T)] d t .
\end{aligned}
$$

II절에서와 같이 $k$ 가 trapezoid의 상승구간 길이를 나 타내고, $s(n)$ 을 식 (6)과 같이 정의한다면 $n$ 값이 식 (7) 의 조건을 만족할 때 $s(n)$ 은 최대값에 도달한다.

$$
\begin{aligned}
& s(n)=\sum_{i=0}^{n}[v(i)-v(i-k)] . \\
& \left\{\begin{array}{c}
s(n)-s(n-k) \geq 0 \\
s(n+1)-s(n+1-k) \leq 0
\end{array}\right\} .
\end{aligned}
$$

그림 8은 trapezoid 신호에 식 (6)을 적용한 결과이며

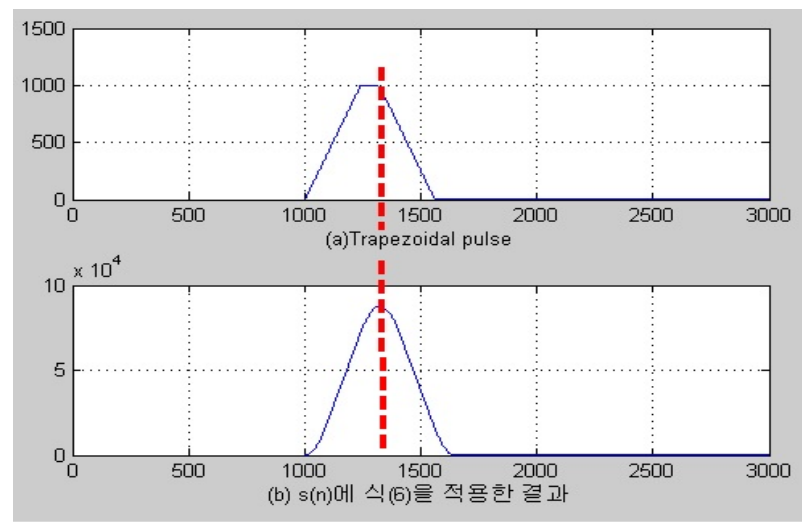

그림 8. (a) Trapezoidal pulse
(b) 식(6)을 적용한 결과

Fig. 8. (a) Trapezoidal pulse,

(b) results obtained by equation 6 .

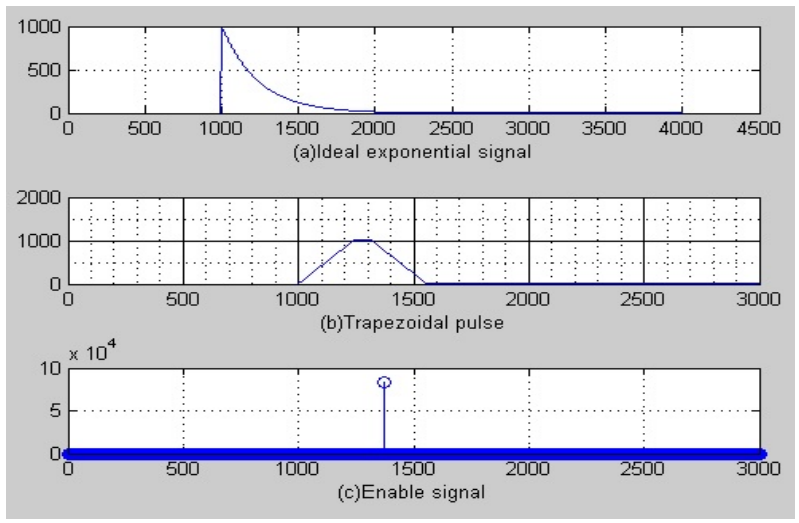

그림 9. (a) Ideal exponential signal

(b) Trapezoidal pulse (c) Enable signal

Fig. 9. (a) Ideal exponential signal,

(b) Trapezoidal pulse and (c) Enable signal.

trapezoid 신호 flat-top 끝 부분에서 $s(n)$ 이 최대값에 도달함을 보인다.

식 (6)을 이용하여 최대값을 결정하기 위해서는 먼 저 최대값이 $M$ 인 ideal 신호로 시뮬레이션 하여 $s(n)$ 을 계산하고 $s(n)$ 과 $M$ 의 비로부터 scale 값을 구한다. 이후 임의의 신호가 입력되면 각 신호에 대해 $s(n)$ 의 최대값을 구한 후, 미리 계산된 scale 값으로 나누어 입력신호의 최대값을 구한다. 그림 9 는 최대값 $M=1,000$ 인 입력신호에 대해 $s(n)$ 을 구한 결과이며 $s(n)$ 의 최대값은 82,895이므로 scale 값은 82.895이다. 실제 trapezoid 신호가 입력되면 $s(n)$ 의 최대값을 구한 후 미리 계산된 스케일 값인 82.895로 나누어 입력신호 의 최대값을 구한다.

\section{2. 제안한 최대값 검출 알고리즘}

제안한 알고리즘으로 trapezoidal 펄스의 flat-top 부

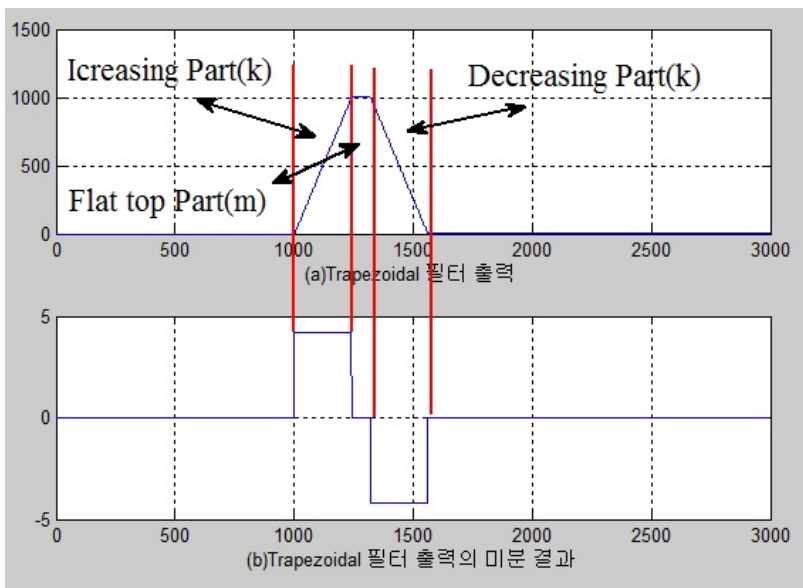

그림 10. Trapezoidal 필터의 미분 결과

Fig. 10. Differenced trapezoidal pulse. 
분을 결정하기위해 먼저 다음과 같이 trapezoidal 펄스 를 미분한다.

$$
d(n)=v u(n+1)-v u(n) .
$$

그림 10은 trapezoidal 펄스를 미분한 결과이며 $d(n)$ 은 trapezoidal 펄스의 increasing, flat-top, decreasing part에 따라 각각 positive, zero, negative 값을 갖는다. 따라서 $d(n)$ 값을 이용하여 trapezoidal 펄스의 각 부분 들을 구분할 수 있다.

그림 11 은 제안한 최대값 검출 알고리즘의 블록도 이 다. 최대값을 결정하기 위해 총 74 개의 레지스터를 이 용하여 입력되는 trapezoidal 펄스의 값을 순서대로 저 장한다. 그림 10에 보인 바와 같이 decreasing part의

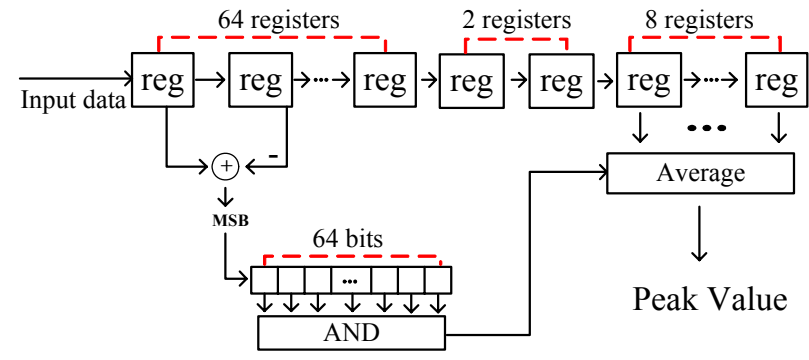

그림 11. 제안한 최대값 검출 알고리즘 블록도

Fig. 11. Block diagram of proposed peak detection algorithm.

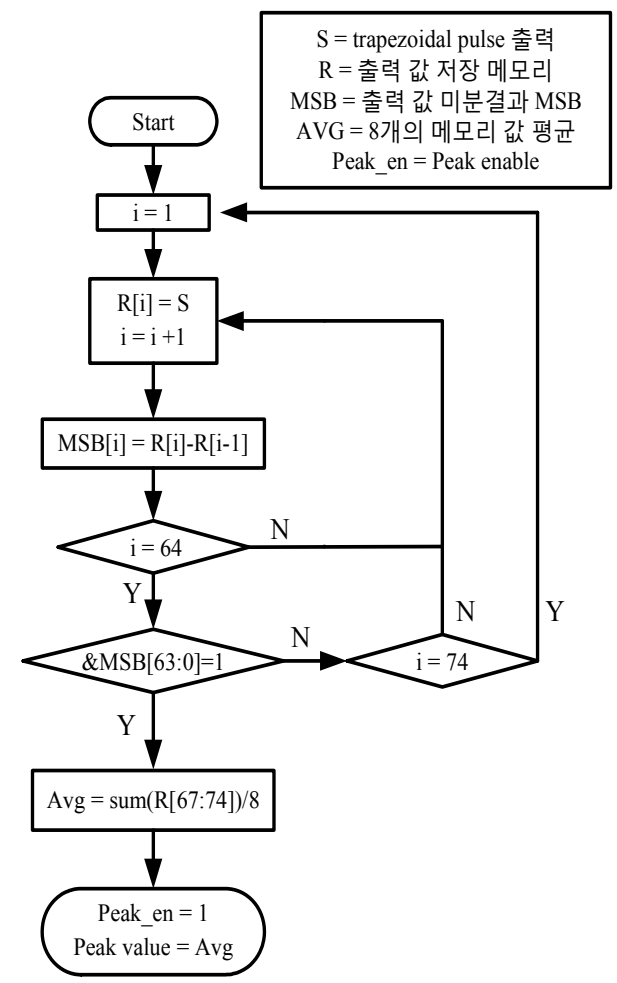

그림 12. 제안 알고리즘의 순서도

Fig. 12. Flowchart of proposed algorithm.
미분 값 들은 모두 음수 이므로 연속적인 64개 입력신 호를 미분하여 $\mathrm{MSB}$ 들이 모두 1이면 decreasing part가 검출된 것으로 간주하고 그 이전 10 개의 레지스터 중 마지막 8개의 레지스터에 저장된 값을 평균하여 입력신 호의 최대값으로 결정한다. 그림 12 는 제안한 최대값 검출 알고리즘의 순서도 이다.

\section{3. 시뮬레이션 결과}

그림 13은 MATLAB을 이용한 기존 알고리즘과 제 안한 알고리즘의 시뮬레이션 결과이다. 그림 13(a)는 $\mathrm{XRF}$ 시스템용 테스트신호 발생장치로부터 입력된 exponential 신호이며 ideal peak value는 196.05이다. 그림 13(b)는 trapezoidal 필터 출력이며 그림13(c)와 그 림 13(d)는 각각 제안 알고리즘 및 기존 알고리즘을 이 용한 최대값 계산결과이다. 두 알고리즘은 모두 정확하 게 최대값 위치를 찾았지만 검출 된 최대값의 오차를 비교하였을 때 표 2에 보인 바와 같이 제안한 알고리즘 에 의한 최대값의 오차는 기존 알고리즘에 의한 최대값 의 오차의 $29 \%$ 에 불과함을 알 수 있다.

표 3은 peak value가 100 1500인 입력신호에 대해

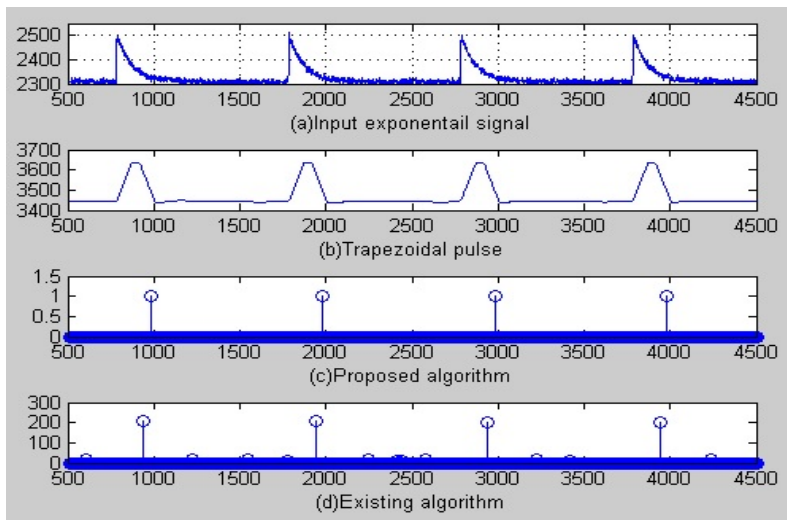

그림 13. (a) 입력 신호 (b) Trapezoidal 필터 출력 결과 (c) 제안 알고리즘 출력결과 (d) 기존 알고리즘 출력결과

Fig. 13. (a) Input signal, (b) output of trapezoidal filter, (c) output of proposed algorithm and (d) output of existing algorithm.

표 2. 그림 13의 입력신호에 대한 peak value 계산

Table 2. Peak value computation for the input signal in Fig. 13.

\begin{tabular}{|c|c|c|c|c|}
\hline \multirow{2}{*}{$\begin{array}{c}\text { Ideal peak } \\
\text { value }\end{array}$} & \multicolumn{2}{|c|}{ 제안 알고리즘 } & \multicolumn{2}{c|}{ 기존 알고리즘 } \\
\cline { 2 - 5 } & $\begin{array}{c}\text { peak } \\
\text { value }\end{array}$ & error & $\begin{array}{c}\text { peak } \\
\text { value }\end{array}$ & error \\
\hline 196.05 & 197.125 & 1.075 & 199.7575 & 3.7075 \\
\hline
\end{tabular}


표 3. Peak Value 시뮬레이션 결과 비교

Table 3. Comparison of peak value simulation results.

\begin{tabular}{|c|c|c|c|c|}
\hline \multirow{2}{*}{$\begin{array}{l}\text { Ideal } \\
\text { peak } \\
\text { value }\end{array}$} & \multicolumn{2}{|c|}{ 제안 알고리즘 } & \multicolumn{2}{|c|}{ 기존 알고리즘 } \\
\hline & $\begin{array}{l}\text { peak } \\
\text { value }\end{array}$ & error & $\begin{array}{l}\text { peak } \\
\text { value }\end{array}$ & error \\
\hline 100 & 99.733 & 0.267 & 98.661 & 1.339 \\
\hline 150 & 150.867 & -0.867 & 150.034 & -0.034 \\
\hline 200 & 199.967 & 0.033 & 203.982 & -3.982 \\
\hline 250 & 250.200 & -0.200 & 248.649 & 1.351 \\
\hline 300 & 301.600 & -1.600 & 303.950 & -3.950 \\
\hline 350 & 350.433 & -0.433 & 352.501 & -2.500 \\
\hline 400 & 397.533 & 2.467 & 396.374 & 3.626 \\
\hline 450 & 451.833 & -1.833 & 453.556 & -3.556 \\
\hline 500 & 498.633 & 1.367 & 499.142 & 0.858 \\
\hline 550 & 551.200 & -1.200 & 552.838 & -2.838 \\
\hline 600 & 598.367 & 1.633 & 600.923 & -0.923 \\
\hline 650 & 651.033 & -1.033 & 650.932 & -0.932 \\
\hline 700 & 701.067 & -1.067 & 702.654 & -2.654 \\
\hline 750 & 750.100 & -0.100 & 748.902 & 1.098 \\
\hline 800 & 800.367 & -0.367 & 799.792 & 0.208 \\
\hline 850 & 851.333 & -1.333 & 846.125 & 3.875 \\
\hline 900 & 899.267 & 0.733 & 899.412 & 0.588 \\
\hline 950 & 948.467 & 1.533 & 947.868 & 2.132 \\
\hline 1000 & 1000.933 & -0.933 & 1000.305 & -0.305 \\
\hline 1500 & 1500.700 & -0.700 & 1503.238 & -3.238 \\
\hline $\begin{array}{c}\text { Average } \\
\text { error }\end{array}$ & & 0.985 & & 1.999 \\
\hline
\end{tabular}

제안 알고리즘과 기존 알고리즘을 적용하여 peak value 를 계산한 결과이다. 노이즈의 크기는 -15 에서 +15 이다. 표 3에 보이는 바와 같이 평균 오차를 비교했을 때 제 안 알고리즘에 의한 오차는 기존 알고리즘에 의한 오차 의 $49.3 \%$ 이다.

기존 알고리즘은 스케일 값의 계산 및 나눗셈 과정을 포함하고 있으나 제안한 알고리즘은 레지스터와 덧셈 및 간단한 게이트들로 구성되어서 효율적인 하드웨어 구현이 가능하다.

\section{IV. 시뮬레이션 결과}

그림 14는 그림 2의 XRF 시스템을 구현한 테스트 보드이다. FPGA chip은 Altera Cyclone III (EP3C16F144C8)를 사용하였으며 Verilog $\mathrm{HDL}$ 을 이용 하여 설계하였다. Quartus $\Pi$ 를 사용하여 시스템을 시 뮬레이션 하였으며 2,179개의 로직 elements를 이용했 고 chip 전체의 $14 \%$ 를 사용하였다. 검출된 최대값들을 일정시간 동안 메모리의 특정 위치에 누적하여 히스토

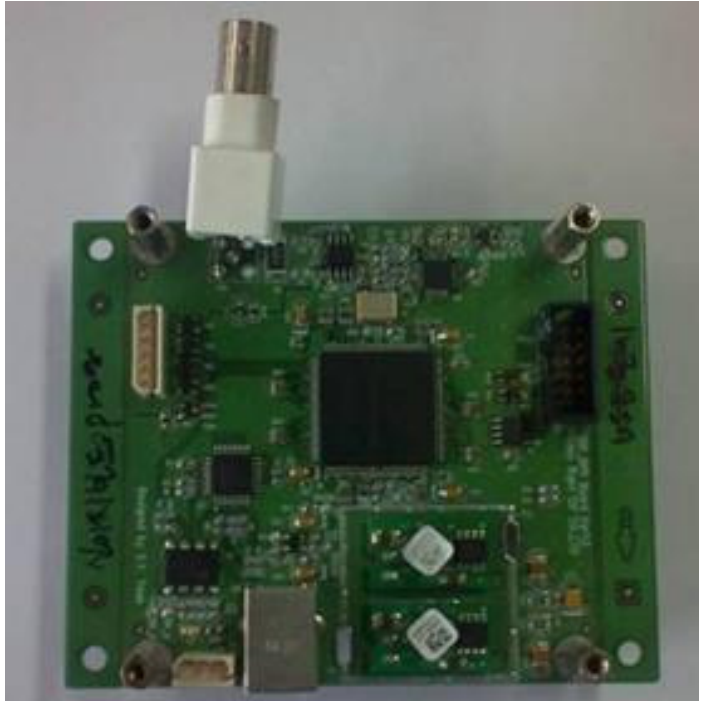

그림 14. 제작 한 테스트 보드

Fig. 14. Implemented test board.

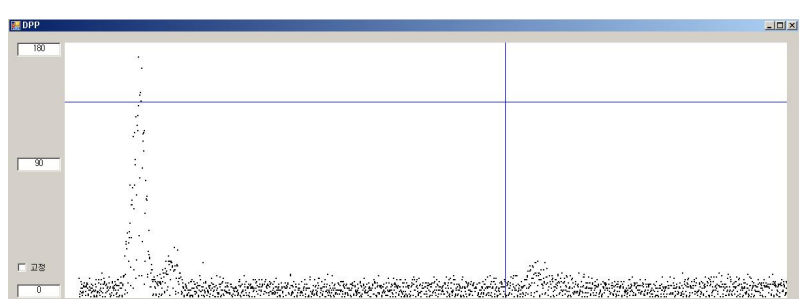

그림 15. 제안한 시스템의 측정 결과

Fig. 15. Result of Proposed systems.

그램을 작성하며 작성된 히스토그램이 테스트보드의 최 종 출력이다. 상위 시스템에서는 히스토그램을 분석하 여 측성시료의 특성을 파악한다.

그림 15 는 실제 원소의 신호를 측정 하였을 때의 출 력 결과이며 성공적으로 동작됨을 보인다.

\section{V. 결 론}

본 논문에서는 XRF 시스템용 trapezoidal 필터의 구 조를 분석하고 trapezoidal 필터의 효율적인 하드웨어 구현 방안을 제시 하였다. 또한 최대값 검출 알고리즘 을 제안하여 기존 알고리즘과 비교하였을 때 잡음에 강 하고 보다 정확한 최대값이 검출됨을 보였다. 시뮬레이 션을 통하여 제안한 알고리즘은 기존의 알고리즘에 비 해 오차가 약 $49.3 \%$ 정도까지 감소됨을 보였다.

기존 알고리즘은 덧셈뿐만 아니라 scale 상수의 계산 및 나눗셈을 포함 하고 있으나 제안한 알고리즘은 레지 스터와 덧셈 및 간단한 게이트들을 이용하여 구현 가능 하므로 하드웨어 면에서 경제적으로 구현할 수 있다.

마지막으로 제안한 $\mathrm{XRF}$ 시스템을 검증하기 위해 실 
제 X-선 신호를 입력으로 테스트하여 성공적으로 동작 함을 확인 하였다.

\section{REFERENCES}

[1] Rene E. Van Grieken, Andrzej A. Markowicz Handbook of X-Ray Spectrometry, Marcel Dekker, 2002.

[2] P. W. Nicholson, Nuclear Electronics. Wiley, New York, 1974.

[3] F. S. Goulding et al., presented at IEEE NSS, San Francisco, Nov. 1993.

[4] Valentin T Jordanov, and Glenn F. Knoll, "Digital synthesis of pulse shapes in real time for high resolution radiation spectroscopy," in Nuclear Instruments and methods in Physics Research, pp. 337-345, 1994.

[5] Cosimo Imperiale, and Alessio Imperialb, "On nuclear spectrometry pulses digital shaping and processing," in Measurement, vol. 30, Issue 1, pp. 49-73, 2011.

[6] S. M. Hinshaw and D. A. Landis, "A practical approach to ballistic deficit correction," IEEE Trans. on Nuclear Science, vol 37, pp. 374-377, 1990.

[7] Valentin Jordanov, Glenn F. Knoll, "Digital pulse processor using a moving average technique," in IEEE Trans. on Nuclear Science, vol. 40, pp. 764-769, 1993.

저 자 소 개

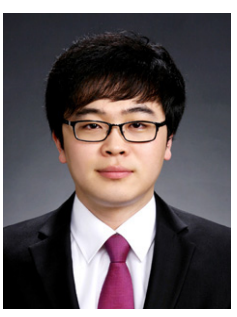

박 철 암(학생회원)

2010년 중국 연변대학교 정보통신 학과 학사 졸업

2012년 전북대학교 전자공학부 석사 졸업

2012년 현재 전북대학교 전자공학부 박사과정.

<주관심분야 : 통신, 신호처리, 반도체>

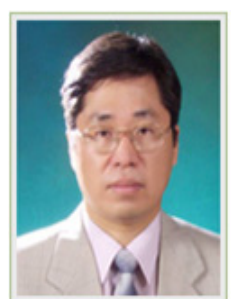

정 진 균(평생회원)

1985년 전북대학교 전자공학 학사 졸업.

1989년 미국 미네소타 주립대학 전기공학 석사 졸업.

1991년 미국 미네소타 주립대학 전기공학 박사 졸업.

<주관심분야 : 통신, 컴퓨터, 신호처리, 반도체> 